\title{
HUBUNGAN ANTARA FAKTOR RISIKO TERJADINYA ISPA DENGAN KEJADIAN ISPA PADA BALITA DI KAWASAN INDUSTRI KABUPATEN GRESIK TAHUN 2017
}

\author{
Almira Sofie Astari, AT. Diana Nerawati, Sukiran Al-Jauhari
}

\begin{abstract}
ABSTRAK
Kejadian ISPA merupakan salah satu penyebab utama kematian pada balita di negara berkembang terutama pneumonia. ISPA pada balita menempati urutan tertinggi di wilayah Kabupaten Gresik. Hal ini dapat terjadi karena Kabupaten Gresik merupakan daerah industri terutama di Kecamatan Kebomas wilayah Puskesmas Kebomas. Terjadinya ISPA pada balita diakibatkan berbagai faktor risiko. Faktor risiko ISPA pada balita adalah zat pencemar $\mathrm{SO}_{2}$, faktor fisik rumah, kepadatan hunian, penggunaan anti nyamuk bakar, status gizi, status imunisasi, riwayat ASI eksklusif, pendidikan ibu, dan anggota keluarga merokok. Penelitian ini bertujuan untuk mengetahui hubungan antara faktor risiko terjadinya ISPA dengan kejadian ISPA pada balita di kawasan industri wilayah Puskesmas Kebomas Kabupaten Gresik.

Penelitian ini menggunakan desain studi case control yang dilakukan mulai Bulan Desember 2016 - Mei 2017 di rumah penduduk sekitar kawasan industri wilayah Puskesmas Kebomas, Kabupaten Gresik. Metode pengambilan sampel yang digunakan adalah teknik simple random sampling dengan besar sampel 112 kasus dan 112 kontrol serta menggunakan analisis univariate dan bivariat (Chi Square).

Hasil penelitian diperoleh zat pencemar $\mathrm{SO}_{2}$ memenuhi syarat baku mutu Pergub No 10 Tahun $2009<262 \mu / \mathrm{Nm}^{3}$, faktor fisik rumah, kepadatan hunian, penggunaan anti nyamuk bakar, kurangnya imunisasi, riwayat ASI eksklusif, pendidikan ibu dan anggota keluarga merokok $p>a(0,05)$, maka tidak ada hubungan dengan kejadian ISPA pada balita. Sedangkan status gizi $p=0,006<a=0,05$, maka berhubungan dan menjadi faktor risiko dengan kejadian ISPA pada balita di kawasan industri wilayah Puskesmas Kebomas. Disimpulkan bahwa faktor risiko yang berhubungan dengan kejadian ISPA pada balita di kawasan industry wilayah Puskesmas Kebomas adalah status gizi dengan besar risiko 2,265 kali. Disarankan masyarakat memberikan gizi yang cukup pada balita, menerapkan konsep dasar desa/kelurahan siaga aktif dalam perilaku hidup bersih dan sehat (Kemenkes, 2010), pihak Dinas Kesehatan (Puskesmas) memberikan penyuluhan dan peneliti lain mengembangkan peneliti dengan faktor risiko lain.
\end{abstract}

Kata Kunci : ISPA, balita, faktor risiko

\section{PENDAHULUAN}

Infeksi Saluran Pernapasan Akut (ISPA) adalah penyakit saluran pernapasan atas atau bawah, biasanya menular yang dapat menimbulkan berbagai spektrum penyakit yang berkisar dari penyakit tanpa gejala atau infeksi ringan sampai penyakit yang parah dan mematikan, tergantung pada patogen penyebabnya, faktor lingkungan, dan faktor pejamu (WHO, 2007).

ISPA adalah penyebab utama tingginya morbiditas (angka kesakitan) dan mortalitas (angka kematian) penyakit menular di dunia. Hampir 4 juta orang meninggal akibat ISPA setiap tahun, 98\%-nya disebabkan oleh infeksi saluran pernapasan bawah. (WHO, 2007).
Pneumonia adalah pembunuh utama balita di dunia, lebih banyak dibanding dengan gabungan penyakit AIDS, malaria dan campak. Di dunia setiap tahun diperkirakan lebih dari 2 juta balita meninggal karena pneumonia (1 Balita/20 detik) dari 9 juta total kematian balita (Kemenkes, 2012). Di Indonesia pneumonia merupakan penyebab $15 \%$ kematian balita, yaitu dipekirakan sebanyak 922.000 balita tahun 2015 (Kementerian Kesehatan RI, 2016). Angka cakupan penemuan pneumonia pada balita di Indonesia sampai dengan tahun 2014 tidak mengalami perkembangan berarti yaitu berkisar antara $20 \%-30 \%$. Pada tahun 2015 terjadi peningkatan menjadi $63,45 \%$. Angka kematian akibat 
pneumonia pada balita sebesar 0,16\%, lebih tinggi dibandingkan dengan tahun 2014 yang sebesar 0,08\%. Pada kelompok bayi angka kematian sedikit lebih tinggi yaitu sebesar $0,17 \%$ dibandingkan pada kelompok umur 1-4 tahun yang sebesar $0,15 \%$ (Kementerian Kesehatan RI, 2016).

Period prevalence Infeksi Saluran Pernafasan Akut (ISPA) di Indonesia berdasarkan diagnosis yang dilakukan tenaga kesehatan dan keluhan penduduk adalah 25\%. Period prevalence ISPA dihitung dalam kurun waktu 1 bulan terakhir. Lima provinsi dengan ISPA tertinggi adalah Nusa Tenggara Timur $(41,7 \%)$, Papua $(31,1 \%)$, Aceh $(30,0 \%)$, Nusa Tenggara Barat $(28,3 \%)$, dan Jawa Timur (28,3\%) (Badan Penelitian dan Pengembangan Kesehatan, 2013). Presentase cakupan penemuan kasus pneumonia Provinsi Jawa Timur Tahun 2011-2014 sebesar 34,33\%, namun belum pernah mencapai target nasional yang telah ditentukan sebesar $100 \%$. Pada tahun 2014, dari 38 kabupaten/kota di Provinsi Jawa Timur, hanya 1 (satu) kabupaten/kota yang telah mencapai target penemuan penderita pneumonia balita, yaitu Kabupaten Gresik (Dinkesprovjatim, 2015). Berdasarkan Evaluasi Capaian P2 ISPA Kabupaten Gresik Tahun 2015, total jumlah angka kejadian ISPA pada balita sebesar 6.852 jiwa (Dinkes Kabupaten Gresik, 2015).

Kabupaten Gresik merupakan wilayah dataran rendah dengan ketinggian 2-12 meter di atas permukaan air laut, kecuali Kecamatan Panceng dan sebagian Kecamatan Ujung Pangkah yang mempunyai ketinggian 25 meter di atas permukaan air laut. Kabupaten Gresik memiliki curah hujan yang relative rendah dan merupakan daerah industri dengan beberapa perusahaan industri besar. Sebagian industri besar dan sedang tersebut kebanyakan tersebar di wilayah Kecamatan Kebomas (BPS 2015). Hal ini memungkinkan terjadi pencemaran udara di wilayah Kecamatan Kebomas sangatlah tinggi. Jenis bahan pencemar udara yang dianggap penting yaitu $\mathrm{CO}_{\mathrm{x}}, \mathrm{SO}_{\mathrm{x}}, \mathrm{NO}_{\mathrm{x}}$ organik volatil, partikulat, oksida fotokimiawi, substansi radioaktif, panas, dan suara (Darmono, 2010). Konsentrasi terbesar yang dihasilkan industri adalah $\mathrm{SO}_{2}$. Dampak dari pencemaran udara tersebut berpengaruh terhadap lingkungan, tumbuhan, serta manusia dan hewan. Terhadap manusia pencemaran udara menyebabkan adanya gangguan pernapasan (seperti ISPA), iritasi pada mata dan telinga, serta timbulnya penyakit tertentu. Dengan keberadaan pemukiman penduduk yang dekat/berada di sekitar industri memudahkan terjadinya gangguan pada manusia. Kejadian ISPA pda balita tertinggi berrada di wilayah Puskesmas Kebomas peiode 2011-2015 (Dinas Kesehatan Kabupaten Gresik, 2015). Hal ini menunjukkan kemungkinan cemaran udara menyebabkan kejadian ISPA di wilayah tersebut.

Faktor risiko pneumonia pada balita adalah kurangnya pemberian ASI eksklusif, gizi buruk, polusi udara dalam ruangan (indoor air pollution), berat badan lahir rendah (BBLR), kepadatan penduduk dan kurangnya imunisasi campak (Kemenkes, 2012). Berbagai penelitian sebelumnya menyebutkan kualitas udara menjadi faktor terjadiya pneumonia pada balita (Layuk \& Noer, 2012). Kualitas udara dipengaruhi oleh seberapa besar pencemaran udara. Pencemaran udara adalah terkontaminasinya udara, baik dalam ruangan (indoor) maupun luar ruangan (outdoor), dengan agen kimia, fisik, atau biologi yang telah mengubah karakteristik alami dari atmosfer (Getrudis, 2010). Pencemaran udara luar salah satunya diakibatkan dari proses industri (Ali, 2007). Sedangkan sumber pencemar udara dalam ruangan adalah anggota keluarga yang mengalami ISPA, anggota keluarga yang merokok, penggunaan obat anti nyamuk bakar, dan penggunaan kayu bakar untuk bahan bakar memasak (Layuk \& Noer, 2012). Asap rokok merupakan gas beracun yang dikeluarkan dari pembakaran produk tembakau yang berbahaya bagi kesehatan. Adanya asap anti nyamuk bakar sederajat dengan merokok sebanyak 100 rokok (Halo Sehat, 2015).

Penelitian ini bertujuan mengetahui hubungan antara faktor risiko terjadinya ISPA dengan kejadian ISPA pada balita di kawasan industri wilayah Puskesmas 
Kebomas Kabupaten Gresik. Faktor risiko yang diteliti dalam penelitian ini adalah outdoor air pollution $\left(\mathrm{SO}_{2}\right)$, faktor fisik rumah (ventilasi, pencahayaan, kelembaban, suhu), kepadatan hunian, penggunaan anti nyamuk bakar, status gizi balita, status imunisasi balita, pemberian ASI eksklusif, pendidikan ibu, dan kebiasaan anggota keluarga merokok.

\section{METODE PENELITIAN}

Penelitian ini menggunakan desain studi case control yang dilakukan di rumah penduduk sekitar kawasan industri wilayah Puskesmas Kebomas, Kabupaten Gresik. Metode pengambilan sampel yang digunakan adalah teknik simple random sampling dengan besar sampel 112 kasus dan 112 kontrol serta menggunakan analisis univariate dan bivariat ( $C h i$ Square).

\section{HASIL DAN PEMBAHASAN \\ Gambaran Faktor Risiko Terjadinya ISPA pada Balita}

Kejadian ISPA pada balita di kawasan industri wilayah Puskesmas Kebomas Kabupaten Gresik tahun sebesar 156 kasus (Data Puskesmas Kebomas Januari - Desember tahun 2016). Hasil identifikasi faktor risiko terjadinya ISPA pada balita di wilayah Puskesmas Kebomas.

\section{Kadar Zat Pencemar $\mathrm{SO}_{2}$}

Tabel 1

KADAR ZAT PENCEMAR $\mathrm{SO}_{2}$ BERDASARKAN DAERAH KONTROL, SUMBER, DAN TERDAMPAK DI KAWASAN INDUSTRI WILAYAH PUSKESMAS KEBOMAS TAHUN 2017

\begin{tabular}{cccccccc}
\hline No & Lokasi / & \multicolumn{2}{c}{ Kontrol } & \multicolumn{2}{c}{ Sumber } & \multicolumn{2}{c}{ Dampak } \\
\cline { 3 - 8 } & Desa & $\left(\boldsymbol{\mu} / \mathbf{N m}^{\mathbf{3}}\right)$ & $\mathbf{T} / \mathbf{M}$ & $\left(\boldsymbol{\mu} / \mathbf{N m}^{\mathbf{3}}\right)$ & $\mathbf{T} / \mathbf{M}$ & $\left(\boldsymbol{\mu} / \mathbf{N m}^{\mathbf{3}}\right)$ & $\mathbf{T} / \mathbf{M}$ \\
\hline 1 & $\mathrm{~A}$ & 67,3 & $\mathrm{M}$ & 100,69 & $\mathrm{M}$ & 81,20 & $\mathrm{M}$ \\
\hline 2 & $\mathrm{~B}$ & 54,05 & $\mathrm{M}$ & 97,54 & $\mathrm{M}$ & 63,1 & $\mathrm{M}$ \\
\hline 3 & $\mathrm{C}$ & 105,60 & $\mathrm{M}$ & 308,21 & $\mathrm{~T}$ & 120,64 & $\mathrm{M}$ \\
\hline 4 & $\mathrm{D}$ & 68,21 & $\mathrm{M}$ & 116,40 & $\mathrm{M}$ & 84,02 & $\mathrm{M}$ \\
\hline 5 & $\mathrm{E}$ & 79,21 & $\mathrm{M}$ & 101,35 & $\mathrm{M}$ & 88,03 & $\mathrm{M}$ \\
\hline 6 & $\mathrm{~F}$ & 205,16 & $\mathrm{M}$ & 514,08 & $\mathrm{~T}$ & 260,24 & $\mathrm{M}$ \\
\hline 7 & $\mathrm{G}$ & 195,13 & $\mathrm{M}$ & 426,11 & $\mathrm{~T}$ & 213,4 & $\mathrm{M}$ \\
\hline
\end{tabular}

Keterangan :

T: Tidak memenuhi syarat $\quad$ M: Memenuhi syarat

Baku Mutu Zat Pencemar SO 2 menurut Pergub Jatim No 10 Tahun $2009262 \mu / \mathrm{Nm}^{3}$

\section{Faktor Fisik Rumah, Kepadatan Hunian, dan Pengggunaan Anti Nyamuk Bakar}

Kondisi fisik rumah yang dimiliki meliputi ventilasi, pencahayaan, suhu, serta kelembaban dengan hasil memenuhi syarat $32 \%$ dan tidak memenuhi syarat $68 \%$. Sedangkan kepadatan hunian rumah dengan memenuhi syarat $34 \%$ dan tidak memenuhi syarat $66 \%$. Dan pengguna anti nyamuk bakar masih ada dengan masih memakai ( $3 \%$ selalu dan $9 \%$ kadang-kadang), serta $88 \%$ tidak memakai.

\section{Status Balita}

Status balita di Kawasan Industri Wilayah Kebomas Gresik terdiri dari gizi, kelengkapan status imunisasi, riwayat ASI. Gizi balita masuk dalam kategori baik $37 \%$. Imunisasi balita termasuk dalam kategori lengkap 91\%. Bayi yang memiliki riwayat ASI eksklusif 64\%.

\section{Status keluarga}

Status keluarga terdiri dari pendidikan ibu dan status merokok anggota keluarga. Pendidikan Ibu di Kawasan Industri Wilayah Puskesmas Kebomas Tahun 201790\% termasuk berpendidikan tinggi dan status merokok $75 \%$. 


\title{
Hubungan Faktor Risiko Terjadinya ISPA dengan Kejadian ISPA pada Balita
}

\author{
Tabel 2
}

HUBUNGAN ZAT PENCEMAR $\mathrm{SO}_{2}$ DENGAN KEJADIAN ISPA PADA BALITA

DI KAWASAN INDUSTRI WILAYAH PUSKESMAS KEBOMAS TAHUN 2017

\begin{tabular}{|c|c|c|c|}
\hline \multirow{3}{*}{ Zat Pencemar $\mathrm{SO}_{2}$} & \multicolumn{2}{|c|}{ Kejadian ISPA } & \multirow{2}{*}{ Total } \\
\hline & Kasus & Kontrol & \\
\hline & F(\%) & F (\%) & F (\%) \\
\hline Tidak Memenuhi Syarat & 0 & 0 & 0 \\
\hline Memenuhi Syarat & $112(50)$ & $112(50)$ & $224(100)$ \\
\hline Total & $112(50)$ & $112(50)$ & $224(100)$ \\
\hline
\end{tabular}

Berdasarkan tabel 2 didapatkan bahwa kadar zat pencemar $\mathrm{SO}_{2}$ pada kontrol dan kasus memenuhi syarat $<262 \mu / \mathrm{Nm}^{3}$ (50\%) (Pergub Jatim No 10 tahun 2009), maka tidak ada hubungan zat pencemar $\mathrm{SO}_{2}$ dengan kejadian ISPA pada balita di kawasan industri wilayah Puskesmas Kebomas Kabupaten Gresik. Dengan demikian zat pencemar $\mathrm{SO}_{2}$ bukan merupakan faktor risiko terjadinya ISPA pada balita di kawasan industri wilayah Puskesmas Kebomas Kabupaten Gresik.

Tabel 3

HUBUNGAN FAKTOR FISIK RUMAH DENGAN KEJADIAN ISPA PADA BALITA

DI KAWASAN INDUSTRI WILAYAH PUSKESMAS KEBOMAS TAHUN 2017

\begin{tabular}{cccc}
\hline \multirow{2}{*}{ Faktor Fisik Rumah } & \multicolumn{2}{c}{ Kejadian ISPA } & \multirow{2}{*}{ Total } \\
\cline { 2 - 3 } & Kasus & Kontrol & \\
\cline { 2 - 3 } & $\mathbf{F ~ ( \% )}$ & $\mathbf{F ~ ( \% )}$ & $\mathbf{F ~ ( \% )}$ \\
\hline Tidak Memenuhi Syarat & $82(53,2)$ & $72(46,8)$ & $154(100)$ \\
\hline Memenuhi Syarat & $30(42,9)$ & $40(57,1)$ & $70(100)$ \\
\hline Total & $112(50)$ & $112(50)$ & $224(100)$ \\
\hline
\end{tabular}

Berdasarkan tabel 3 didapatkan bahwa proporsi responden faktor fisik rumah tidak memenuhi syarat pada kasus ISPA $(53,2 \%)$ lebih tinggi dibandingkan pada kontrol ISPA (46,8\%). Hasil uji Chi Square $\mathrm{p}=0,195(>\mathrm{a})$, maka tidak ada hubungan faktor fisik rumah dengan kejadian ISPA pada balita. Dengan demikian faktor fisik rumah bukan merupakan faktor risiko terjadinya ISPA pada balita di kawasan industri wilayah Puskesmas Kebomas Kabupaten Gresik.

Tabel 4

HUBUNGAN KEPADATAN HUNIAN DENGAN KEJADIAN ISPA PADA BALITA

DI KAWASAN INDUSTRI WILAYAH PUSKESMAS KEBOMAS TAHUN 2017

\begin{tabular}{|c|c|c|c|}
\hline \multirow{3}{*}{ Kepadatan Hunian } & \multicolumn{2}{|c|}{ Kejadian ISPA } & \multirow{2}{*}{ Total } \\
\hline & Kasus & Kontrol & \\
\hline & F (\%) & F (\%) & F (\%) \\
\hline Tidak Memenuhi Syarat & $76(51,4)$ & $72(48,6)$ & $148(100)$ \\
\hline Memenuhi S & $36(47,4)$ & $40(52,6)$ & $76(100)$ \\
\hline Total & $112(50)$ & $112(50)$ & $224(100)$ \\
\hline
\end{tabular}

Berdasarkan tabel 4 didapatkan bahwa proporsi responden kepadatan hunian tidak memenuhi syarat pada kasus ISPA
$(51,4 \%)$ lebih tinggi dibandingkan pada kontrol ISPA (48,6\%). Hasil uji Chi Square $\mathrm{p}=0,672(>\mathrm{a})$, maka tidak ada 
hubungan kepadatan hunian dengan kejadian ISPA pada balita di kawasan industri wilayah Puskesmas Kebomas Kabupaten Gresik. Dengan demikian kepadatan hunian bukan merupakan faktor risiko terjadinya ISPA pada balita di kawasan industri wilayah Puskesmas Kebomas Kabupaten Gresik.

Tabel 5

HUBUNGAN ANTI NYAMUK BAKAR DENGAN KEJADIAN ISPA PADA BALITA

DI KAWASAN INDUSTRI WILAYAH PUSKESMAS KEBOMAS TAHUN 2017

\begin{tabular}{|c|c|c|c|}
\hline \multirow{3}{*}{$\begin{array}{c}\text { Anti Nyamuk } \\
\text { Bakar }\end{array}$} & \multicolumn{2}{|c|}{ Kejadian ISPA } & \multirow{2}{*}{ Total } \\
\hline & Kasus & Kontrol & \\
\hline & F (\%) & F (\%) & F (\%) \\
\hline$\overline{Y a}$ & $25(54,3)$ & $21(45,7)$ & $46(100)$ \\
\hline Tidak & $87(48,9)$ & $91(51,1)$ & $178(100)$ \\
\hline Total & $112(50)$ & $112(50)$ & $224(100)$ \\
\hline
\end{tabular}

Berdasarkan tabel 5 didapatkan bahwa proporsi responden penggunaan anti nyamuk bakar pada kasus ISPA (54,3\%) lebih tinggi dibandingkan kontrol ISPA $(45,7 \%)$. Hasil uji Chi Square $\mathrm{p}=0,576$ $(>a)$, maka tidak ada hubungan penggunaan anti nyamuk bakar dengan kejadian ISPA pada balita di kawasan industri wilayah Puskesmas Kebomas Kabupaten Gresik. Dengan demikian penggunaan anti nyamuk bakar bukan merupakan faktor risiko terjadinya ISPA pada balita di kawasan industri wilayah Puskesmas Kebomas Kabupaten Gresik.

Tabel 6

HUBUNGAN STATUS GIZI BALITA DENGAN KEJADIAN ISPA PADA BALITA DI KAWASAN INDUSTRI WILAYAH PUSKESMAS KEBOMAS TAHUN 2017

\begin{tabular}{lccc}
\hline \multirow{2}{*}{ Status Gizi Balita } & \multicolumn{2}{c}{ Kejadian ISPA } & \multirow{2}{*}{ Total } \\
\cline { 2 - 3 } & Kasus & Kontrol & \\
\cline { 2 - 3 } & $\mathbf{F ( \% )}$ & $\mathbf{F ( \% )}$ & $\mathbf{F ( \% )}$ \\
\hline Kurang & $81(57,4)$ & $60(42,6)$ & $141(100)$ \\
\hline Baik & $31(37,3)$ & $52(62,7)$ & $83(100)$ \\
\hline \multicolumn{1}{c}{ Total } & $112(50)$ & $112(50)$ & $224(100)$ \\
\hline
\end{tabular}

Berdasarkan tabel 6 didapatkan bahwa proporsi responden status gizi balita kurang pada kasus ISPA $(57,4 \%)$ lebih tinggi dibandingkan pada kontrol ISPA $(42,6 \%)$. Hasil uji Chi Square $\mathrm{p}=0,006$ $(<a)$, maka ada hubungan status gizi balita dengan kejadian ISPA pada balita di kawasan industri wilayah Puskesmas Kebomas Kabupaten Gresik. Dengan demikian status gizi balita merupakan faktor risiko terjadinya ISPA pada balita di kawasan industri wilayah Puskesmas Kebomas Kabupaten Gresik ( $\mathrm{OR}=2,265$; $95 \%$ CI $=1,299-3,949)$. 
Tabel 7

HUBUNGAN STATUS IMUNISASI BALITA DENGAN KEJADIAN ISPA PADA BALITA

DI KAWASAN INDUSTRI WILAYAH PUSKESMAS KEBOMAS TAHUN 2017

\begin{tabular}{llcc}
\hline \multirow{2}{*}{$\begin{array}{c}\text { Status Imunisasi } \\
\text { Balita }\end{array}$} & \multicolumn{2}{c}{ Kejadian ISPA } & \multirow{2}{*}{ Total } \\
\cline { 2 - 3 } & Kasus & Kontrol & \\
\cline { 2 - 3 } & $\mathbf{F ~ ( \% )}$ & $\mathbf{F ~ ( \% )}$ & $\mathbf{F ~ ( \% )}$ \\
\hline Kurang & $14(66,7)$ & $7(33,3)$ & $21(100)$ \\
\hline Lengkap & $98(48,3)$ & $105(51,7)$ & $203(100)$ \\
\hline \multicolumn{1}{c}{ Total } & $112(50)$ & $112(50)$ & $224(100)$ \\
\hline
\end{tabular}

Berdasarkan tabel 7 didapatkan bahwa proporsi responden status imunisasi balita tidak lengkap pada kasus ISPA $(66,7 \%)$ lebih tinggi dibandingkan pada kontrol ISPA $(33,3 \%)$. Hasil uji Chi Square $\mathrm{p}=$ $0,169(>a)$, maka tidak ada hubungan status imunisasi balita dengan kejadian
ISPA pada balita di kawasan industri wilayah Puskesmas Kebomas Kabupaten Gresik. Dengan demikian status imunisasi balita bukan merupakan faktor risiko terjadinya ISPA pada balita di kawasan industri wilayah Puskesmas Kebomas Kabupaten Gresik.

Tabel 8

HUBUNGAN RIWAYAT ASI EKSKLUSIF DENGAN KEJADIAN ISPA PADA BALITA DI KAWASAN INDUSTRI WILAYAH PUSKESMAS KEBOMAS TAHUN 2017

\begin{tabular}{cccc}
\hline \multirow{2}{*}{$\begin{array}{c}\text { Riwayat ASI } \\
\text { Eksklusif }\end{array}$} & \multicolumn{2}{c}{ Kejadian ISPA } & \multirow{2}{*}{ Total } \\
\cline { 2 - 3 } & Kasus & Kontrol & \\
\cline { 2 - 3 } & $\mathbf{F ( \% )}$ & $\mathbf{F ~ ( \% )}$ & $\mathbf{F ( \% )}$ \\
\hline Tidak Eksklusif & $78(54,2)$ & $66(45,8)$ & $144(100)$ \\
\hline Eksklusif & $34(42,5)$ & $46(57,5)$ & $80(100)$ \\
\hline Total & $112(50)$ & $112(50)$ & $224(100)$ \\
\hline
\end{tabular}

Berdasarkan tabel 8 didapatkan bahwa proporsi responden riwayat ASI tidak eksklusif pada kasus ISPA (54,2\%) lebih tinggi dibandingkan pada kontrol ISPA $(45,8 \%)$. Hasil uji Chi Square $\mathrm{p}=0,125$ $(>a)$, maka tidak ada hubungan riwayat ASI eksklusif dengan kejadian ISPA pada balita di kawasan industri wilayah Puskesmas Kebomas Kabupaten Gresik. Dengan demikian riwayat ASI eksklusif bukan merupakan faktor risiko terjadinya ISPA pada balita di kawasan industri wilayah Puskesmas Kebomas Kabupaten Gresik.

Tabel 9

HUBUNGAN PENDIDIKAN IBU DENGAN KEJADIAN ISPA PADA BALITA DI KAWASAN INDUSTRI WILAYAH PUSKESMAS KEBOMAS TAHUN 2017

\begin{tabular}{lccc}
\hline \multirow{2}{*}{$\begin{array}{c}\text { Pendidikan } \\
\text { Ibu }\end{array}$} & \multicolumn{2}{c}{ Kejadian ISPA } & \multirow{2}{*}{ Total } \\
\cline { 2 - 3 } & Kasus & Kontrol & \\
\cline { 2 - 3 } & $\mathbf{F ( \% )}$ & $\mathbf{F ~ ( \% )}$ & $\mathbf{F ( \% )}$ \\
\hline Rendah & $15(65,2)$ & $8(34,8)$ & $23(100)$ \\
\hline Tinggi & $97(48,3)$ & $104(51,7)$ & $201(100)$ \\
\hline \multicolumn{1}{c}{ Total } & $112(50)$ & $112(50)$ & $224(100)$ \\
\hline
\end{tabular}


Berdasarkan tabel 9 didapatkan bahwa proporsi responden pendidikan ibu rendah pada kasus ISPA $(65,2 \%)$ lebih tinggi dibandingkan pada kontrol ISPA $(34,8 \%)$. Hasil uji Chi Square $p=0,187(>a)$, maka tidak ada hubungan pendidikan ibu dengan kejadian ISPA pada balita di kawasan industri wilayah Puskesmas

Kebomas Kabupaten Gresik. Dengan demikian pendidikan ibu bukan merupakan faktor risiko terjadinya ISPA pada balita di kawasan industri wilayah Puskesmas Kebomas Kabupaten Gresik.

Tabel 10

HUBUNGAN ANGGOTA KELUARGA MEROKOK DENGAN KEJADIAN ISPA PADA BALITA DI KAWASAN INDUSTRI WILAYAH PUSKESMAS KEBOMAS TAHUN 2017

\begin{tabular}{lccc}
\hline \multirow{2}{*}{$\begin{array}{l}\text { Anggota } \\
\text { Keluarga } \\
\text { Merokok }\end{array}$} & \multicolumn{2}{c}{ Kejadian ISPA } & \multirow{2}{*}{ Total } \\
\cline { 2 - 3 } & Kasus & Kontrol & \\
\cline { 2 - 3 } & $\mathbf{F}(\%)$ & $\mathbf{F}(\%)$ & $\mathbf{F}(\%)$ \\
\hline Berat & $47(51,1)$ & $45(48,9)$ & $92(100)$ \\
\hline Sedang & $45(58,4)$ & $32(41,6)$ & $77(100)$ \\
\hline Tidak & $20(36,4)$ & $35(63,6)$ & $55(100)$ \\
\hline \multicolumn{1}{c}{ Total } & $112(50)$ & $112(50)$ & $224(100)$ \\
\hline
\end{tabular}

Berdasarkan tabel 10 didapatkan bahwa proporsi responden anggota keluarga yang memiliki kebiasaan merokok pada kasus ISPA $(51,1 \%)$ lebih tinggi dibandingkan pada kontrol ISPA $(48,9 \%)$. Hasil uji Chi Square p = 0,091 (>a), maka tidak ada hubungan kebiasaan anggota keluarga merokok dengan kejadian ISPA pada balita di kawasan industri wilayah Puskesmas Kebomas Kabupaten Gresik. Dengan demikian kebiasaan anggota keluarga merokok bukan merupakan faktor risiko terjadinya ISPA pada balita di kawasan industri wilayah Puskesmas Kebomas Kabupaten Gresik.

\section{Kesimpulan}

Zat pencemar $\mathrm{SO}_{2}$ memenuhi syarat baku mutu Pergub No 10 Tahun $2009<262$ $\mu / \mathrm{Nm}^{3}$, faktor fisik rumah, kepadatan hunian, penggunaan anti nyamuk bakar, kurangnya imunisasi, riwayat ASI eksklusif, pendidikan ibu dan anggota keluarga merokok $p>a(0,05)$, maka tidak ada hubungan dengan kejadian ISPA pada balita. Sedangkan status gizi $p=0,006<a=0,05$, maka berhubungan dan menjadi faktor risiko 2,265 kali dengan kejadian ISPA pada balita di kawasan industri wilayah Puskesmas Kebomas.

\section{Saran}

1. Bagi Masyarakat

Berdasarkan konsep dasar desa/kelurahan siaga aktif dalam perilaku hidup bersih dan sehat (Kemenkes 2010) :

a. Memberikan gizi yang cukup pada balita.

b. Memberikan ASI eksklusif pada balita.

c. Menerapkan konsep dasar desa/kelurahan siaga aktif .

d. Mengurangi atau tidak menggunakan anti nyamuk bakar.

e. Memberikan imunisasi lengkap pada balita.

f. Menguragi atau tidak merokok.

2. Bagi Instansi Pendidikan

a. Memberikan penyuluhan serta promosi tentang penyakit ISPA pada balita.

b. Melakukan kerjasama dengan Dinas Kesehatan guna memonitoring.

3. Bagi Peneliti Lain

Diharapkan pada peneliti lain agar mengembangkan penelitian ini dengan faktor risiko lain, desain penelitian, metode pengambilan sampel yang berbeda agar didapatkan hasil penelitian yang lebih sempurna dan lebih baik lagi 


\section{DAFTAR PUSTAKA}

Ali, A.R., 2007. Kebijakan Pencemaran Udara.

http://arali.2008.tiles.wordpress.co $\mathrm{m} / 2008 / 08 /$ kebijakan-pencemaranudara1.pdf.

BPS, 2015. Kabupaten Gresik Dalam Angka 2015. http://gresikkab.go.id/profil/gresik dalam angka.

Darmono, 2010. Lingkungan Hidup dan Pencemaran. Jakarta:UI-Press.

Dinkes Kabupaten Gresik, 2015. Evaluasi Capaian P2 ISPA Kabupaten Gresik Tahun 2015, Gresik: Dinas Kesehatan Kabupaten Gresik.

Dinkesprovjatim, 2015. Profil Kesehatan Provinsi Jawa Timur Tahun 2014. , p.115.

http://www.depkes.go.id/resources /download/profil/PROFIL KES PRO VINSI 2014/15 Jatim 2014.pdf.

Halo Sehat. 2015. 8 Bahaya Obat Nyamuk Bakar dan Semprot dari Bahan Pembuatannya.

http://halosehat.com/farmasi/obat/ 8-bahaya-obat-nyamuk-bakar-dansemprot-dari-bahan-

pembuatannya. [diakses 23 Juli 2017]
Kemenkes, 2012. Pedoman Pengendalian Infeksi Saluran Pernafasan Akut, Jakarta: Kemenkes RI.

Kemenkes RI. 2016. Profil Kesehatan Indonesia $2015 . \quad$ Jakarta. Kementerian Kesehatan Republik Indonesia

Layuk, R.R. \& Noer, N.N., 2012. Faktor Yang Berhubungan Dengan Kejadian Ispa Pada Balita Di Lembang Batu Sura ' Factors Related With Incidence Of Ari To The Under Five Children In Lembang Of Batu Sura' Alumni Epidemiologi FKM Universitas Hasanuddin , Makassar Bagian Epidemiologi FKM Un. , pp.1-12. Available at: http://repository.unhas.ac.id/bitstre am/handle/123456789/4279/RIBKA RERUNGLAYUK(K11109326).pdf?se quence $=1$.

WHO, 2007. Pencegahan dan Pengendalian Infeksi Saluran Pernapasan Akut (ISPA) yang Cenderung Menjadi Epidemi dan Pandemi di Fasilitas Pelayanan Kesehatan. Pedoman Interim WHO, p.12.

http://apps.who.int/iris/bitstream/1 0665/69707/14/WHO_CDS_EPR_20 07.6_ind.pdf 